\title{
Herb-induced liver injury (HILI) with 12,068 worldwide cases published with causality assessments by Roussel Uclaf Causality Assessment Method (RUCAM): an overview
}

\author{
Rolf Teschke $^{1}$, Axel Eickhoff ${ }^{1}$, Johannes Schulze², Gaby Danan ${ }^{3}$ \\ ${ }^{1}$ Division of Gastroenterology and Hepatology, Department of Internal Medicine II, Klinikum Hanau, Hanau, Academic Teaching Hospital of the \\ Medical Faculty, Goethe University Frankfurt/ Main, Frankfurt/Main, Germany; ${ }^{2}$ Institute of Occupational, Social and Environmental Medicine, \\ Goethe-University Frankfurt/Main, Frankfurt/Main, Germany; ${ }^{3}$ Pharmacovigilance consultancy, Paris, France \\ Contributions: (I) Conception and design: All authors; (II) Administrative support: None; (III) Provision of study materials or patients: A Eickhoff, \\ J Schulze, G Danan; (IV) Collection and assembly of data: None; (V) Data analysis and interpretation: All authors; (VI) Manuscript writing: All \\ authors; (VII) Final approval of manuscript: All authors. \\ Correspondence to: Rolf Teschke, MD. Professor of Medicine, Division of Gastroenterology and Hepatology, Department of Internal Medicine II, Klinikum \\ Hanau, Teaching Hospital of the Goethe University of Frankfurt/Main, Leimenstrasse 20, D-63450 Hanau, Germany. Email: rolf.teschke@gmx.de.
}

\begin{abstract}
Herbal products including herbal medicines are worldwide used in large amounts for treating minor ailments and for disease prevention. However, efficacy of most herbal products has rarely been well documented through randomized controlled trials in line with evidence-based medicine concepts, which could be used to estimate the benefit/risk ratio. Instead, much better documented are adverse reactions such as liver injury associated with the consumption of some herbal products, so called herb-induced liver injury (HILI), which represents a clinical challenge. In order to establish HILI as valid diagnosis, the use of a diagnostic algorithms such as Roussel Uclaf Causality Assessment Method (RUCAM) is widely recommended, although physicians in some countries are reluctant to use RUCAM for their HILI cases. This review on worldwide HILI and RUCAM, developed as part of the artificial intelligence ideas, reveals that China is the leading country with 24 publications on HILI cases that were all assessed for causality using RUCAM, followed by Korea with 15 reports, Germany with 9 reports, the US with 7 reports, and Spain with 6 reports, whereas the remaining countries provided less than 4 reports. The total number of assessed HILI cases is 12,068 worldwide derived from 80 publications but in each report HILI case numbers were variable in a range from 1 up to 6,971. This figure compares with 46,266 cases of drug-induced liver injury (DILI) published worldwide from 2014 to early 2019 also assessed for causality by RUCAM. The original version of RUCAM was validated and established in 1993 and updated in 2016 that should be used in future HILI cases. RUCAM is an objective, structured, and validated method, specifically designed for liver injury. It is a scoring system including case data elements to be assessed and scored individually to provide a final score in five causality gradings. Among the 11,404/12,068 HILI (94.5\%) cases assessable for evaluation, causality gradings were highly probable in $4.2 \%$, probable in $15.5 \%$, possible in $70.3 \%$, and unlikely or excluded in $10.0 \%$. To improve the future reporting of RUCAM based HILI cases, recommendations include the strict adherence to instructions outlined in the updated RUCAM and, in particular, to follow prospective data collection on the cases to ensure completeness of case data. In conclusion, RUCAM can well be used to assess causality in suspected HILI cases, and additional efforts are now required to increase the quality of the reported cases.
\end{abstract}

Keywords: Liver injury; drug-induced liver injury (DILI); herb-induced liver injury (HILI); Roussel Uclaf Causality Assessment Method (RUCAM)

Received: 16 March 2020; Accepted: 13 April 2020; Published: 25 July 2021.

doi: $10.21037 /$ tgh-20-149

View this article at: http://dx.doi.org/10.21037/tgh-20-149 


\section{Introduction}

Herb-induced liver injury (HILI) is a rare adverse reaction associated with the consumption of herbal products like herbal medicines or more specifically regulatory approved herbal drugs and presents clinical features similar to those of drug-induced liver injury (DILI) (1-3). Validated specific biomarkers are not commonly available to diagnose either HILI, perhaps with the exception of a few herbs (4), or DILI (5) with the required degree of likelihood. It is therefore necessary to use a strong and reliable causality assessment method (CAM) such as RUCAM (Roussel Uclaf Causality Assessment Method) to diagnose liver injury (1-6). The original RUCAM was validated and established in $1993(7,8)$ with an update in $2016(9)$.

A substantial variability was observed among countries whenever liver injury cases had been evaluated using published data $(6,10)$. Their common analytical basis was the use of RUCAM in liver injury cases. However, a systematic worldwide analysis of liver injury cases based on causality assessment by RUCAM was restricted so far to DILI in a study of 46,266 cases presented as case reports or case series published from 2014 to early 2019 (6). No such systematic evaluation of RUCAM based HILI cases worldwide focusing on countries is available.

This analysis presents for the first time an overview on the international literature with focus on the worldwide use RUCAM in HILI cases and critically evaluates the quality of the published reports with respect to completeness of case data and the proportion of highly probable and probable causality gradings. The case evaluation was extended to lower gradings with the most likely alternative cause. Finally, the extent of published reports of HILI cases not assessed for causality using RUCAM was evaluated and compared with well assessed HILI cases showing high causality gradings.

\section{Literature search and source}

The PubMed database was used to identify publications for the following terms: Herb induced liver injury; Herbal medicine; Herbal traditional medicine; HILI; Traditional Chinese medicines; TCM; RUCAM; Roussel Uclaf Causality Assessment Method. Search terms were used either alone or combined with other terms. Articles in English were preferred and checked for the suitability to be included in the review article. This excluded, for instance, reports from China published in Chinese language but allowed inclusion of Chinese reports published in English language journals with transparent data accessible for peer review. Search period ended on 14 March 2020.

\section{Definitions}

Only herbs causing HILI were considered, which include a variety of herbal products and more specifically herbal traditional medicines with herbal traditional Chinese medicines (TCMs) or traditional occidental medicines (TOM) in general, and regulatory approved herbal drugs. This definition excludes a priori any of the so called herbal dietary supplements (HDS) from the present analysis.

\section{Countries with RUCAM based HILI cases, RUCAM specificities, and HILI epidemiology}

\section{Countries worldwide and regions}

Scientists from countries throughout the world including regions of Asia, Europe, North America, South America, South Africa, and Australia published HILI cases after assessment for causality using RUCAM (Table 1), referencing in particular in alphabetical order to reports from Australia $(11,12)$, Austria (13), Brazil (14), China with reports from 2006 until 2019 (15-36), China with more recent reports of 2020 (37,38), and Colombia (39), France (40), Germany (41-49), India (50,51), Italy (52-54), and Japan $(55,56)$, followed by Korea (57-71), Singapore $(72,73)$, South Africa (74), Spain (75-80), Sweden (81), Switzerland (82), Turkey (83), and finally the US (84-91).

The current analysis of scientists favoring the use of RUCAM showed that China is on top with 24 publications on RUCAM based HILI cases, followed by Korea with 15 reports, Germany with 9 reports, the US with 7 reports, and Spain with 6 reports, whereas the remaining countries provided less than 3 reports. Among the reports, the number of HILI cases may vary from 1 to 6,971 . Considering all RUCAM based cases, the total number of 12,068 HILI cases worldwide includes 443 cases from nonAsian countries versus 11,625 cases from Asian countries. Therefore, non-Asian countries contributed with $3.7 \%$ to the worldwide cases as opposed to Asian countries with $96.3 \%$. This difference could be partly due to the known high herbal consumption in Asian countries as compared with non-Asian countries but the exact data of herbal consumption is unknown. 


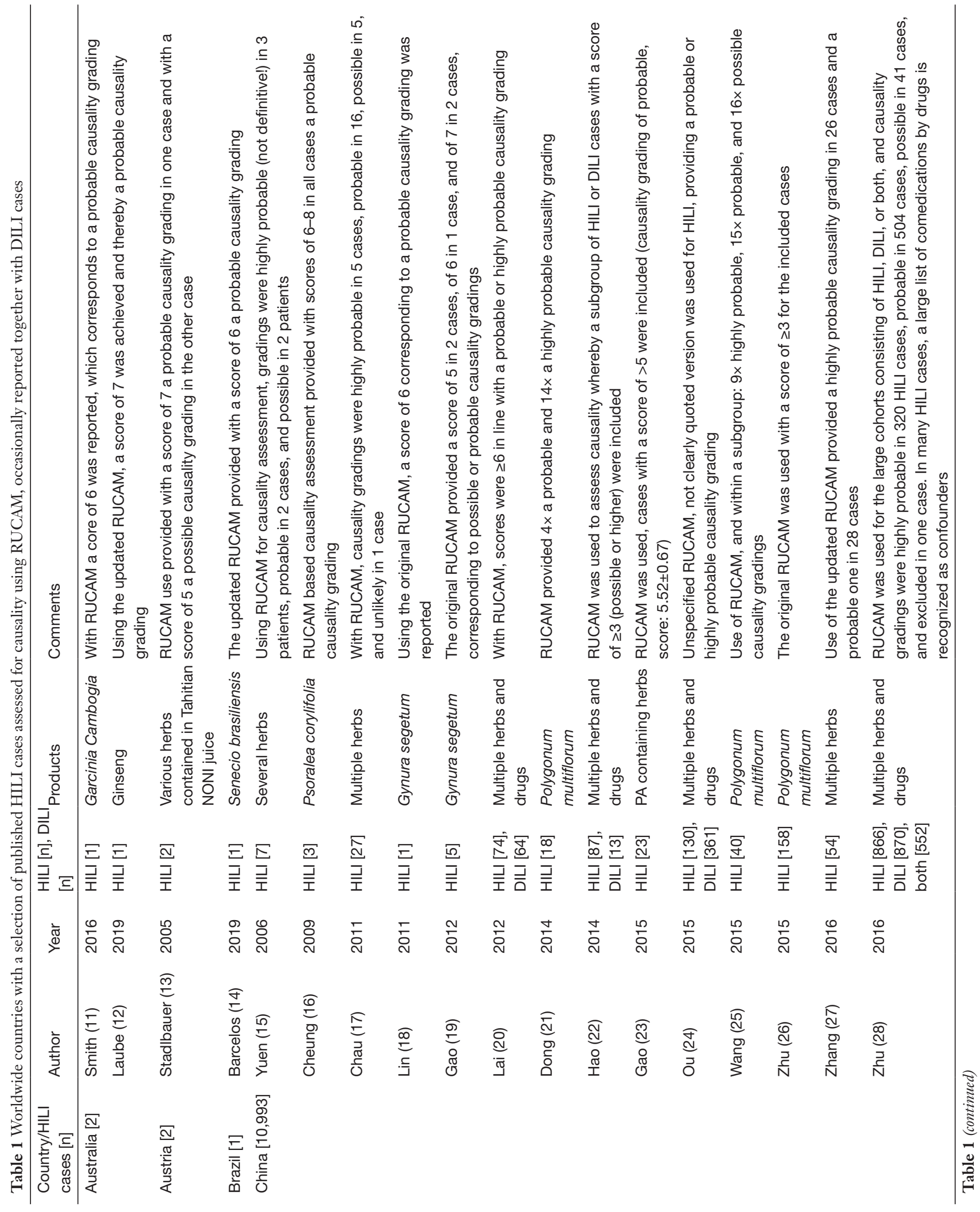




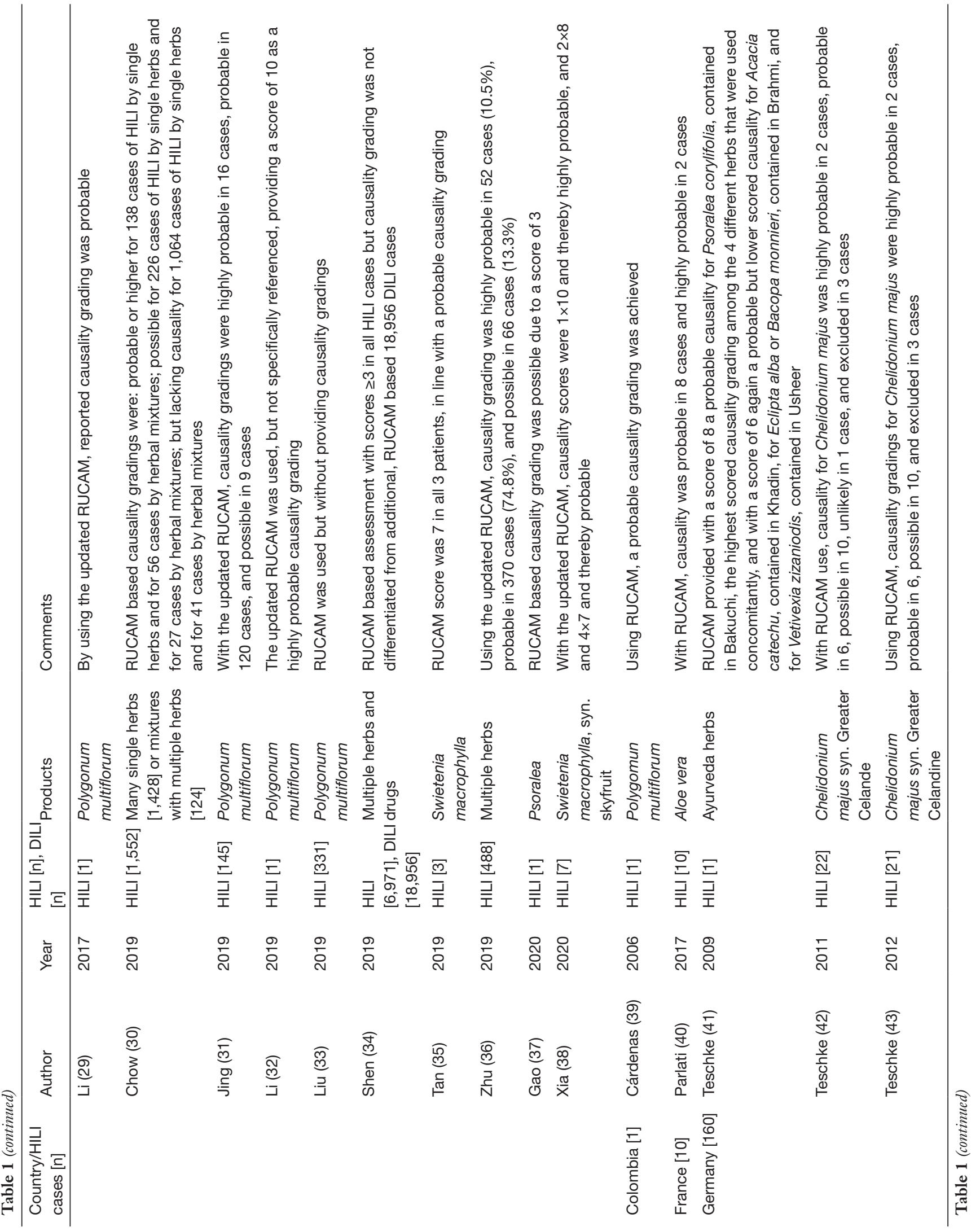




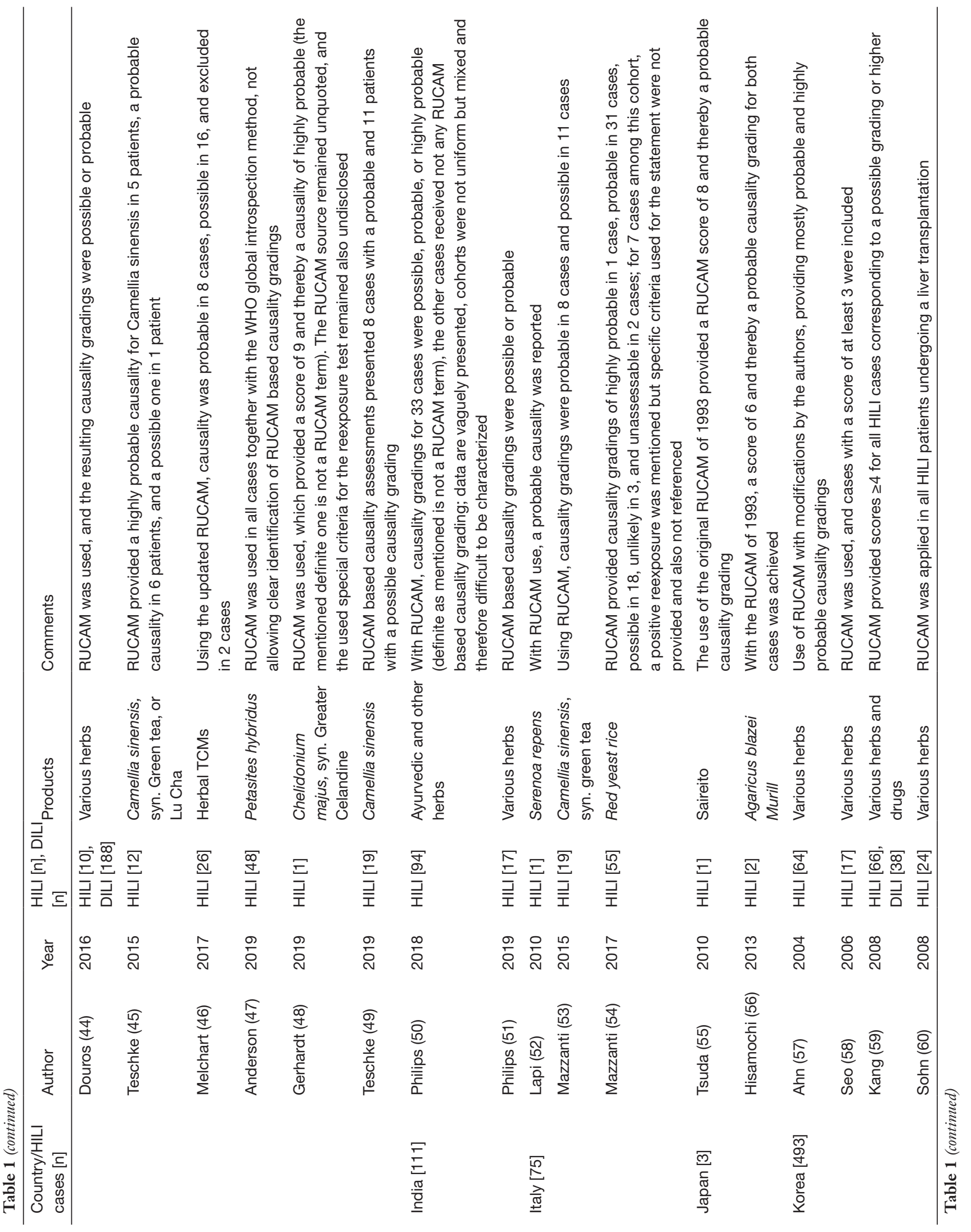




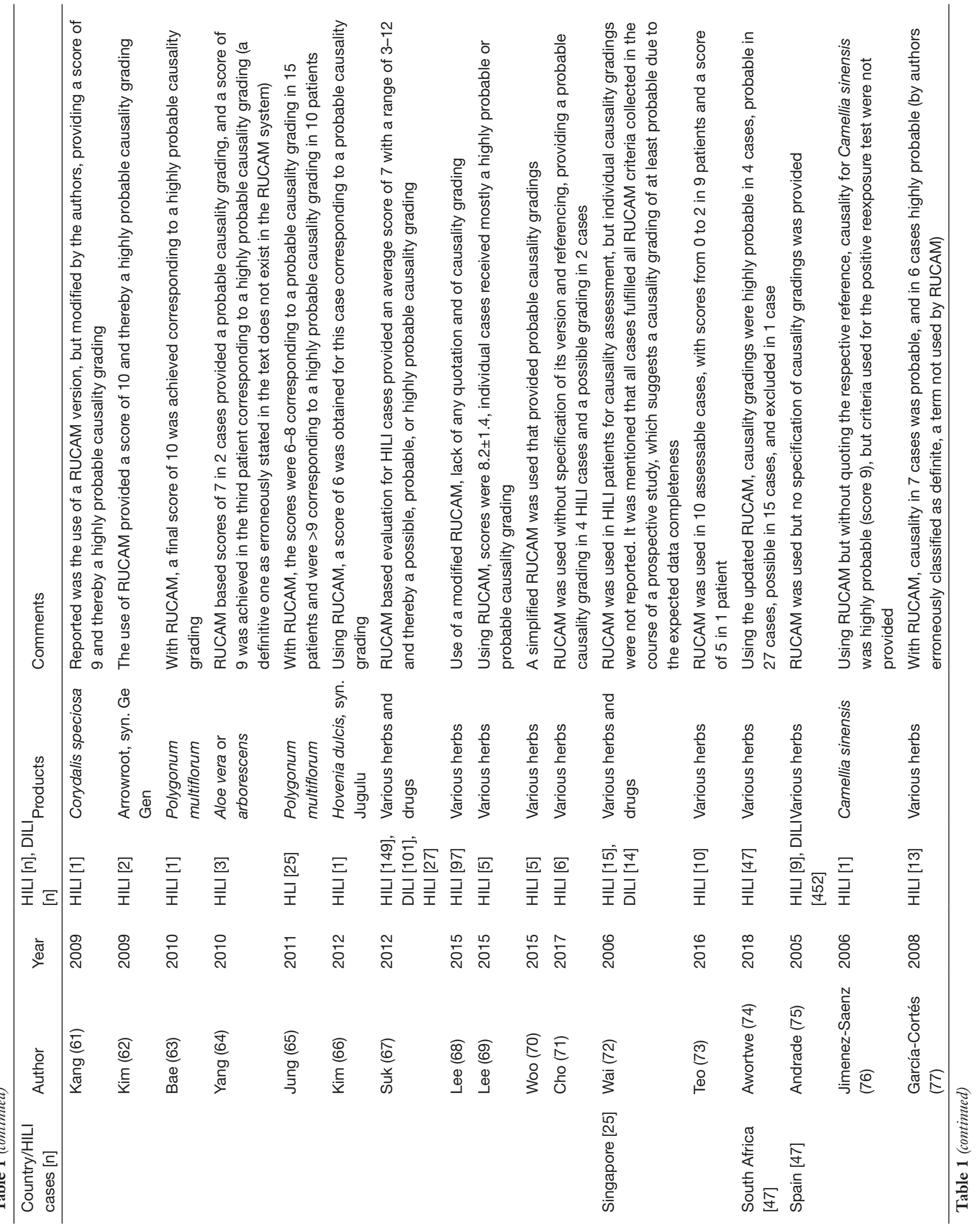




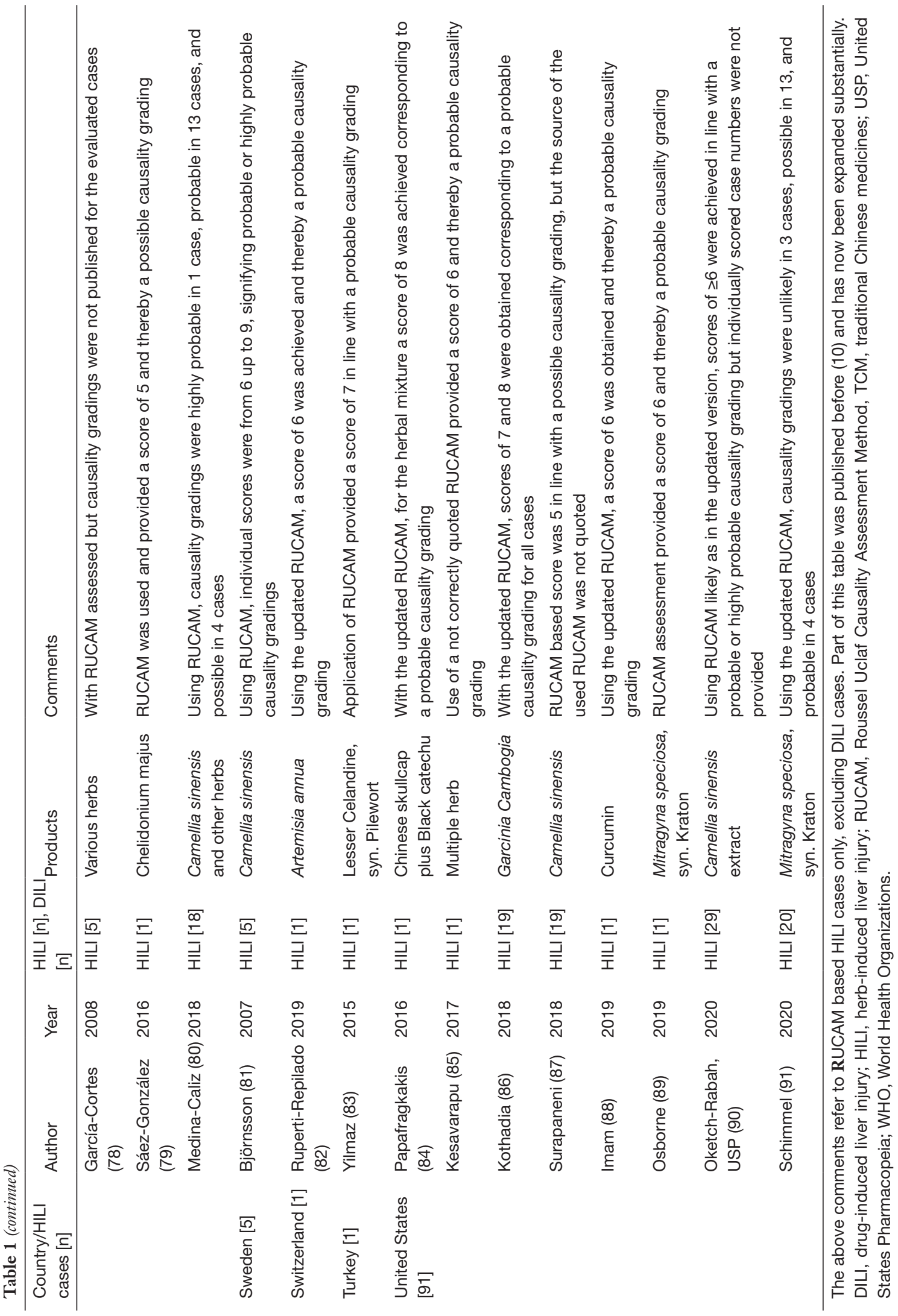




\section{HILI assessed for causality by RUCAM}

For the majority of the listed HILI reports (Table 1), the original RUCAM of 1993 was used, with providing the accurate reference $(7,8)$, but recent publications applied more frequently the updated RUCAM, first available since 2016 (9). In addition, other patients with clinically assumed HILI have likely been assessed for causality using RUCAM in a private practice or clinical setting without submitting these cases to publications. These unquantifiable cases would subsequently increase the number of the listed cases (Table 1). Occasionally, another CAM was used in addition to RUCAM, conditions that might disturb results of causality gradings and prevent comparison with HILI cohorts using RUCAM alone.

In a few reports, the highest causality grading for HILI was erroneously reported as certain or definite (Table 1); none of these terms are used in RUCAM publications (7-9) as any biological result including those of a human disease cannot be classified higher as highly probable, there is nothing certain or definite in any biological setting.

\section{Causality gradings and case data quality}

The variability of RUCAM based causality gradings is of interest (Table 1) and merits further comments (Table 2). From the initially published 12,068 HILI cases, only 11,404 cases $(94.5 \%)$ contained sufficient data on RUCAM based causality gradings (Table 2). Consequently, in 5.5\% of the cases causality gradings were not provided although RUCAM was applied in these cases. Regrettably, this omission invalidates the conclusions proposed in these case reports of this small HILI subgroup and represents waste of time, financials, and energy of scientists, editors, and reviewers. In more detail, based on 11,404 assessable HILI cases, causality gradings were highly probable in $4.2 \%$ of the cases, probable in $15.5 \%$ of the cases, possible in $70.3 \%$ of the cases, and other gradings like unlikely or excluded in $10.0 \%$ of the cases (Table 2). Unquestionable, HILI cases best qualified for further case characterization regarding specific herbs are those with a highly probable or a probable causality grading, both represent $19.7 \%$ of the assessable cases (Table 2). High causality gradings were commonly achieved under the following conditions: first, data are derived from studies with a prospective design, allowing for straight forward collection of data sets and their completeness; second, single cases were assessed prospectively, asking for all RUCAM based specific elements in advance at time of first suspected diagnosis 


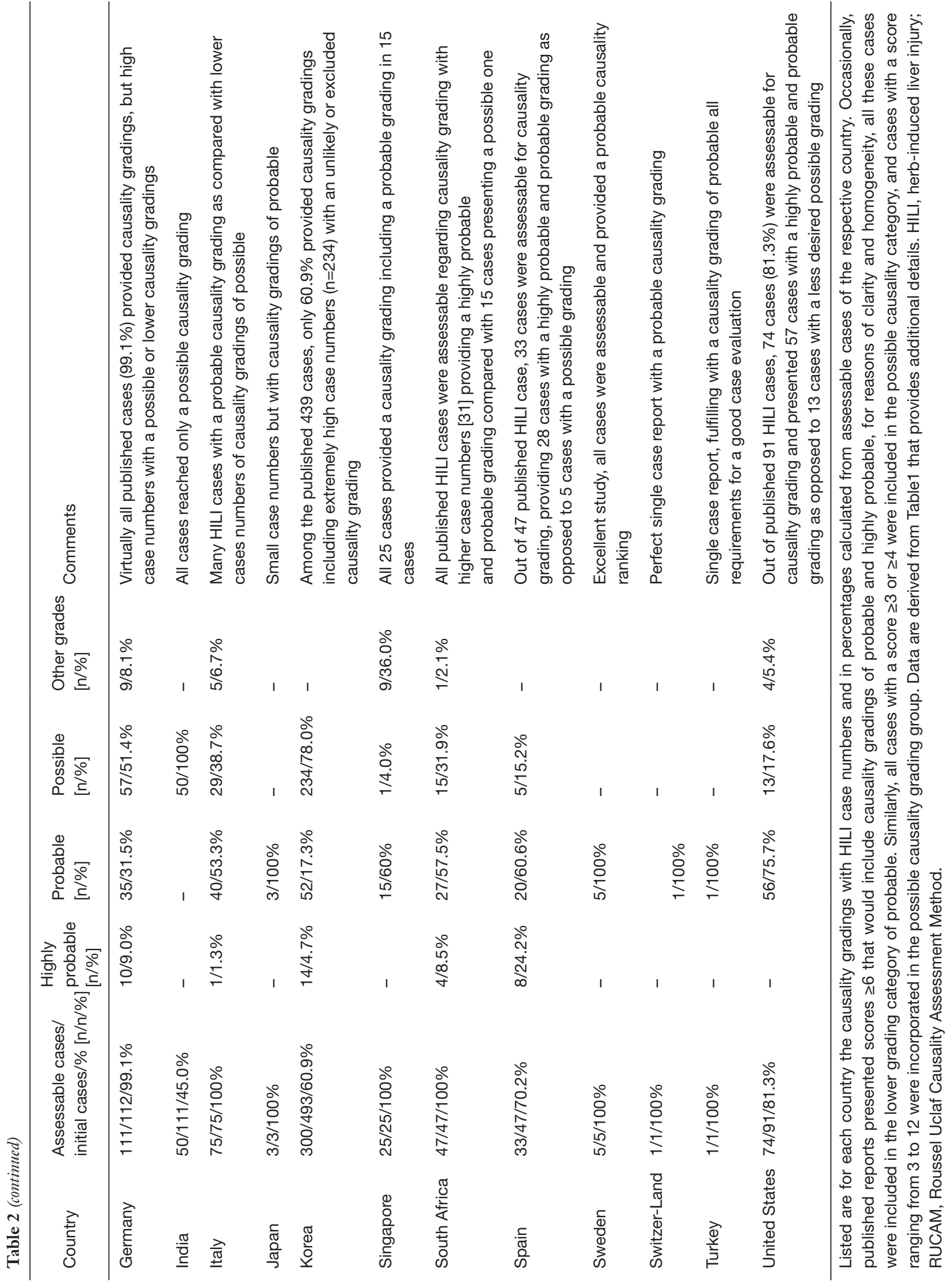


and ensuring complete data and high gradings upon final evaluation; third, cases with causality not meeting highly probable or probable gradings may have been deleted prior to publication to provide cohort homogeneity. In line with these considerations, HILI cases with possible causality gradings are mostly the result of insufficient data, obtained from retrospective studies or single cases. It has repetitively and strongly been proposed that RUCAM works best in a prospective setting of data collection to ensure complete data with chances of high causality gradings (6-9,92-95). Of note, among the assessable cases and based on case numbers, best values for highly probable causality gradings were provided in China with 447 cases representing $4.2 \%$ of all assessable cases in this country (Table 2).

\section{RUCAM specificities}

RUCAM with its favored specificities has seemingly a good run worldwide as evidenced by assessing causality in 46,266 DILI cases (6) and now confirmed in 12,068 HILI cases (Table 1), with many details and proposals ensuring its correct application, providing appropriate case data quality and allowing for high causality gradings (6-9,92-95). For DILI, a RUCAM-DILI Case Quality (RDCQ) system has been proposed (6) that can be translated into HILI as well because many essentials apply to both DILI and HILI. RUCAM is objective, structured, validated, quantitative, transparent, user friendly, and specifically designed for liver injury by assessing liver specific elements, for which individual scores are attributed (9). Authors used RUCAM smoothly in their 12,068 HILI cases (Table 1) and 46,266 DILI cases (6). Problems were not reported, confirming its user-friendly use (9).

Summing up the individual element scores of RUCAM provides a final score and resulting causality grading: score $\leq 0$, excluded causality; $1-2$, unlikely; $3-5$, possible; 6-8, probable; $\geq 9$, highly probable (9). For future HILI case characterization, only cases with probable or highly probable causality gradings should be included in study cohorts. The updated RUCAM should be the preferred version with all its specificities to be used in future cases of both HILI and DILI (9). The aim of RUCAM is to clearly specify causality gradings using scores of assessed key elements rather than applying obscure percentages of causality ranges, leaving room for arbitrary modifications as known from the recent study from China and the US that published causality upgrading from possible to probable gradings likely in order to increase the power of conclusions (34). In addition, and as confirmed in court for another US study, intentional uptonings of RUCAM scores from possible to probable gradings invalidate published conclusions as outlined in detail $(96,97)$ and recently $(10)$, disregarding ethics commonly prevailing within the scientific community (6).

Actually and in retrospect, RUCAM is now to be seen as part of the recently promoted artificial intelligence (AI) ideas which calls for using algorithms to prevent arbitrary opinions, concepts early recognized already at the time of the introduction of RUCAM in the DILI and HILI community in $1993(7,8)$. In fact, RUCAM is an objective diagnostic algorithm that overcomes previous attempts of causality assessment by the vague and subjective global introspection (GI) approach $(94,95)$. GI is not liver specific, not structured, and not based on specific elements to be scored individually, and there is good evidence that RUCAM outperforms any other CAM, which are still caught up in the pre-RUCAM and pre-AI era and thereby neglecting the use of preferred diagnostic algorithms. It is said that most of these CAMs will not survive the next years unless all RUCAM specificities are incorporated one by one into the other CAMs.

As an important specificity, RUCAM was the first CAM that ever recognized the importance of various types of liver injury for a robust causality assessment (7-9). Based on thorough case analyses, three types of liver injury pattern emerged that showed striking differences of their clinical features and courses, with focus on challenge, dechallenge, and reexposure characteristics (9). Using results from laboratory analyses of alanine aminotransferase (ALT) and alkaline phosphatase (ALP) and not from liver histology, these three types were classified as hepatocellular injury, cholestatic liver injury, and mixed liver injury. Due to the variability of their clinical features, specific key items and individual scores had to be defined for each of the three liver injury types. Subsequent analyses led to the conclusion that for the causality assessment, only two instead of three RUCAM versions are necessary, one for the hepatocellular injury and the other one for the cholestatic liver injury and the mixed liver injury with its predominant cholestatic features, with details outlined earlier (9). Types of liver injury were randomly mentioned in the HILI reports under consideration (Table 1).

In line with recommendations presented in the updated RUCAM, liver injury is defined by increased serum activities of liver tests (LTs) with the following thresholds (9): ALT of at least $5 \times$ upper limit of normal (ULN) and/or 
of ALP of at least $2 \times$ ULN provided ALP is of hepatic origin, both best assessed simultaneously on the day of first presentation of suspected liver as outlined in 2016 (9). In the original RUCAM of 1993, ALT thresholds of $2 \times$ ULN were lower $(7,8)$ but these values should not be applied anymore to ensure exclusion of cases reflecting unspecific, clinically not relevant liver injury, liver adaptation, more frequent cause of liver injury such as nonalcoholic steatohepatitis (NASH), or simple LT abnormality. In the current analysis, some HILI reports were assessed with low threshold values (Table 1), which increased the total number of suspected HILI cases. The current ALT and ALP threshold values of 2016 (9) are also considered as relevant in China (98). For sake of comparability, in future publications of HILI, these thresholds should be used and mentioned in the method section. In fact, actual threshold information is often lacking in HILI publications (Table 1).

Another specificity of RUCAM is the optional rather than mandatory inclusion of results from unintentional reexposure tests, but prerequisite for case inclusion is the application of strict criteria before and during reexposures (9). In detail, to classify a reexposure test as positive, criteria are required. For the hepatocellular injury, ALT levels before reexposure (designated as baseline ALT or ALTb) and reexposure ALT levels (designated as ALTr). The reexposure test is positive if ALTb is $<5 \times$ ULN and ALTr is $\geq 2 \times$ ALTb, negative if one or both criteria are not fulfilled, and uninterpretable if data are lacking for one or both criteria. For the cholestatic or the mixed liver injury, the criteria and interpretation of results are similar, with ALT replaced by ALP (9). A positive reexposure test result is a hallmark of DILI and HILI and recognized by a maximum achievable score of 3 in RUCAM (9). Clearly, reexposure test is unintentional since intentional test is unethical due to high risks of severe outcome of liver injury. Results of reexposure tests using defined criteria have rarely been reported in the HILI cases under consideration (Table 1). However, high causality gradings in HILI are easily achievable without the need of these tests. In other studies, claimed positive reexposure test results from reexposures have rarely been confirmed following reassessment due to absence of strict criteria $(99,100)$. For instance, among 34 HILI cases with initially reported positive reexposure tests, $61.8 \%$ of the cases actually fulfilled established test criteria, with negative tests in $17.6 \%$ and uninterpretable tests in $20.6 \%$ of the cases (100).

RUCAM considers alternative causes in a transparent approach (9). This is needed because many published HILI cases are not true HILI but such cases have to be attributed to alternative causes (101). Cohorts with inclusion of true HILI cases and liver diseases unrelated to herbal use but due to alternative causes lead inevitably to wrong descriptions of HILI features and conclusions. DILI cohorts show also flaws in the assessment of alternative causes $(102,103)$.

Simultaneous use of RUCAM with other CAMs reported in few cases (Table 1) should be discouraged because it clouds the results of causality gradings. Modification of RUCAM also mentioned in a few publications (Table 1) should also be discouraged because the changes have not been validated. Clearly, RUCAM assesses causality for the herbal product in toto and cannot differentiate between the toxicity of the phytochemicals or the components willingly added to the products such as chemical drugs as adulterants or accidently contaminated by impurities, heavy metals, or toxins.

Obviously, RUCAM is unable to replace methods of herb authentication, an important issue as in some HILI cases where the used herbs had been misidentified. RUCAM also has no extra key element for quality issues of the herbal product (9), resulting from batch to batch variability, plant circadian clock system, biotic or abiotic plant stress, seasonal variation, or non-optimum area of harvest (104).

\section{Coborts of HILI and DILI}

Opposed to European reports, Asian reports often and regretfully included a mix of HILI and DILI cases (Table 1), conditions not facilitating a characterization of HILI features resulting in high confusion in the offending products (Table 3). This analysis extends the previously one of HILI and DILI cases that were not based on RUCAM (105). In future studies a clear separation of HILI cases from DILI cases is indispensable. Difficult to reconcile is also the tendency to identify liver injury by herbs as DILI rather than correctly as HILI as outlined in some reports (Table 1). This may lead to confusion. Consequently and by definition, herbs cause HILI and not DILI, and HILI cases cannot be subsumed under the DILI cases.

In Asian countries analyzing the ratio of HILI to DILI (Table 1) provides variable results, best explained by differences in the primary study design favoring either HILI or DILI (Table 3). In European countries, however, RUCAM based HILI cases prevail over RUCAM based DILI cases (Table 3). Clearly, the number of reports is small, but both HILI and DILI cases were drawn from the same ethnic population allowing for a more robust comparison. 
Table 3 Selected countries with published HILI cases assessed for causality using RUCAM, reported together with RUCAM based DILI cases

\begin{tabular}{|c|c|c|c|c|c|}
\hline Region & Country & Author & Year & HILI [n], DILI [n] & HILI/DILI ratio \\
\hline \multirow[t]{8}{*}{ Asia } & \multirow[t]{5}{*}{ China } & Lai (20) & 2012 & HILI [74], DILI [64] & 1.16 \\
\hline & & Hao (22) & 2014 & HILI [87], DILI [13] & 6.7 \\
\hline & & Ou (24) & 2015 & HILI [130], DILI [361] & 0.36 \\
\hline & & Zhu (28) & 2016 & HILI [563], DILI [870] & 0.65 \\
\hline & & Shen (34) & 2019 & HILI [6,971], DILI [18,956] & 0.37 \\
\hline & \multirow[t]{2}{*}{ Korea } & Kang (59) & 2008 & HILI [66], DILI [38] & 1.74 \\
\hline & & Suk (67) & 2012 & HILI [149], DILI [101] & 1.48 \\
\hline & Singapore & Wai (72) & 2006 & HILI [5], DILI [14] & 0.36 \\
\hline \multirow[t]{2}{*}{ Europe } & Germany & Douros (44) & 2016 & HILI [10], DILI [188] & 0.05 \\
\hline & Spain & Andrade (75) & 2005 & HILI [9], DILI [452] & 0.02 \\
\hline
\end{tabular}

HILI, herb-induced liver injury; RUCAM, Roussel Uclaf Causality Assessment Method; DILI, drug-induced liver injury.

On a worldwide base, the 12,068 HILI cases (Table 1) are substantially lower as compared with the reported 46,266 DILI cases (6). However, this divergence should not lead to the erroneous conclusion that risks of liver injury are much higher for patients using conventional drugs than those consuming herbal medicines because the population exposed to each product category is unknown.

\section{HILI epidemiology}

Best data of HILI epidemiology can be achieved using a prospective study design that ensures completeness of case data, whereby all cases should be assessed for causality using the updated RUCAM including LT thresholds and causality gradings of probable and highly probable.

Valid data on HILI epidemiology have rarely been reported and are available for a few countries only, but some critical issues remain $(34,46,68,71)$. For instance, a low HILI prevalence was found in a large retrospective single center study from Korea in 27/4,769 patients (0.6\%) with musculoskeletal disorders receiving TCMs (68), with confirmed results through a thorough reevaluation as published by the same group (106). In Korea again, HILI prevalence has been reported from a nationwide multicenter and prospective study with $6 / 1,001$ patients $(0.6 \%)(71)$. These results from one single country as presented by two different groups are surprising and require comments. With $0.6 \%$, identical data of HILI prevalence were achieved $(68,71,106)$, although one group used a retrospective design commonly known for its low case quality $(68,106)$, whereas the other group followed a prospective study design (71). The case definition in both groups using HILI cases was ALT thresholds of at least $3 \times \operatorname{ULN}(68,71,106)$. With higher ALT threshold of $\geq 5 \times$ ULN, HILI case numbers approached the zero range (71). HILI epidemiology is seemingly not a problem in Korea $(68,71,106)$, a situation similar to Germany considering low TCM-related HILI incidence data (46). In the latter report, liver injury data were collected from a prospective, hospital-based and largescale study of 21,470 patients who had no liver disease prior to treatment with herbal TCM. Among these, 26 patients $(0.12 \%)$ experienced HILI defined as ALT values of $\geq 5 \times$ ULN but causality as assessed by the updated RUCAM (9) was probable in only 8 cases, possible in 16 patients and excluded in 2 cases (46).

In China with around 1.4 billion inhabitants, HILI epidemiology is more complex $(34,107)$. In particular, valid epidemiology data of HILI are not available for the population although herbal TCMs are constituents of the Chinese health system. An earlier disputable epidemiology analysis was not RUCAM based and used mixed cohorts of liver injury by drugs, herbs, or complementary and alternative medicines (106). Instead, improvements brought were evident in a recent report focusing on incidence and etiology of DILI in mainland China, which in fact considered both HILI and DILI (34). It was now recognized that the use of RUCAM as a valuable diagnostic algorithm can help assess causality in liver injury cases (34). However, the cohorts still included under the term of DILI not only DILI but also liver injury cases caused by herbal TCM 
and HDS, again presenting the shortcomings of the earlier study (106), not allowing for characterization of HILI epidemiology features (34). Nevertheless, some progress is recognizable because other critical shortcomings have been well identified in the text under the limitation section (34). A new version of this study is promised and will hopefully be published with inclusion of the updated RUCAM of 2016, then without major flaws and after a careful peer review preventing letters to the editor. With the current data and methods, no valid statement is reasonable on HILI epidemiology in China (34). Nevertheless, China is well prepared to present valid data on HILI cases, all assessed by RUCAM to distinguish incidence from prevalence, considering major differences in definitions as outlined earlier (10).

\section{RUCAM based HILI cases without confirmed causality}

There are few HILI cohorts with cases, which lost their initially claimed causality after reassessment with RUCAM (Table 4) (108-112). These cohorts share the common feature of being initially submitted as spontaneous reports to regulatory agencies or governmental institutes, which inappropriately handled the causality assessment of these cases (108). Shortcomings included the failure to initiate a formal and robust causality assessment approach or the use of diagnostic methods that were not validated for liver injury preventing any firm conclusion. However and in spite of these methodological issues, some regulatory agencies including the one in Germany announced a restricted market availability for a previously authorized herbal drug because of the risk of liver injury. Despite formal request, the German regulatory agency BfArM (Bundesinstitut für Arzneimittel und Medizinprodukte) refused access to anonymized case data in order to reassess the cases with RUCAM. However, anonymized case details were readily obtained from the involved manufacturers. Assessments with RUCAM showed insufficient data quality and many confounders such as preexisting liver disease or comedication, leading then to the conclusion that the initially claimed HILI was not substantiated. Finally, via a recent court decision against the German regulatory ban of kava (Piper methysticum) and in support of case analyses mainly from the group of the first author ( $\mathrm{R}$ Teschke), the controversy has now hopefully been settled. According to a comprehensive report published 2015, the administrative court of Cologne in Germany ruled that the available data do not support the alleged liver injury of kava, the herbal anxiolytic drug and traditional herb in Oceania (113). Overall, the number of cases seemed insignificant for the court when compared with the known exposure data of 450 million daily doses in ten years. As the German regulatory agency came under scientific fire, it removed its statements of 2002 from its internet home page, but the file has been preserved by the first author available upon request.

Based on these discussions with the German regulatory agency BfArM and to avoid similar disturbances in the future, manufactures of herbal drugs or other herbal medicines are encouraged to submit suspected HILI cases to regulatory agencies only if suspected cases were assessed for causality with the updated RUCAM (9). If regulatory agencies reach different causality gradings, they will have to explain the divergent results.

There was, however, good news from European Medicines Agency (EMA), formerly located in the UK and now in the Netherlands (Table 4) that HILI cases attributed to black cohosh were reassessed using RUCAM and denied causality for a variety of reasons in virtually all cases (Table 4) (112).

\section{Published HILI cases lacking causality assessment by RUCAM}

Regretfully, some otherwise promising and promotional HILI cases did not benefit from causality assessment by RUCAM (Table 5) as shown in reports originating from Argentina (114), Austria (115), Belgium (116), Canada (117,118), China (107,119-121), France (121,122), Germany (118,123-131), Italy (132,133). Japan (134), the Netherlands (135), New Zealand (136), South Africa (137), Thailand (138), and the US (139-154). RUCAM could have provided substantial support for published conclusions and provided more power to HILI related issues.

\section{Proposals for improved case management with RUCAM}

RUCAM has an excellent run internationally in assessing causality for HILI cases, attributed to its well accepted use worldwide and outperforming over other CAMs. Quality of RUCAM based HILI cases is fairly good but not optimal in some cases. Therefore, in future studies the following points should be considered:

(I) Recommendations as outlined in the updated RUCAM should strictly be followed when assessing 
Table 4 RUCAM based HILI reports with negative or rare causality

\begin{tabular}{|c|c|c|c|c|c|}
\hline Country & Author & Year & $\begin{array}{l}\text { Initially } \\
\text { suspected } \\
\text { HILI [n] }\end{array}$ & Products & Comments \\
\hline \multirow{2}{*}{ Germany } & Teschke (109) & 2010 & HILI [69] & $\begin{array}{l}\text { Actacea racemosa, } \\
\text { formerly Cimicifuga } \\
\text { racemosa, syn. } \\
\text { Black cohosh }\end{array}$ & $\begin{array}{l}\text { Using RUCAM in all } 69 \text { cases, in none of the cases a probable or } \\
\text { highly probable causality grading was evident; causality for Actacea } \\
\text { recemosa was excluded in } 27 \text { cases, unlikely in } 21 \text {, unrelated in } 8 \text {, and } \\
\text { unassessable in } 12 \text { cases; only } 1 / 69 \text { cases received a possible causality } \\
\text { grading }\end{array}$ \\
\hline & Teschke (111) & 2016 & HILI [10] & Petasides hybridus & $\begin{array}{l}\text { Using the updated RUCAM, } 9 / 10 \text { cases received scores from } 0 \text { to } 2 \text {, } \\
\text { equivalent to an excluded or unlikely causality grading, whereas for } \\
1 / 10 \text { cases a score of } 3 \text { was attributed, signifying a low graded possible } \\
\text { causality grading }\end{array}$ \\
\hline $\begin{array}{l}\text { United } \\
\text { Kingdom }\end{array}$ & EMA (112) & 2007 & HILI [47] & $\begin{array}{l}\text { Actacea racemoae, } \\
\text { syn. Cimicifuga } \\
\text { racemose, syn. } \\
\text { Black cohosh }\end{array}$ & $\begin{array}{l}\text { RUCAM used in } 31 \text { cases: cases qualified for unassessable, excluded } \\
\text { or unrelated causality. RUCAM in additional } 16 \text { cases provided causality } \\
\text { gradings: excluded in } 5 \text { cases (scores between } 0 \text { and -2), unlikely (scores } \\
\text { between } 1 \text { and } 2 \text { ) in } 8 \text { cases, possible (scores } 3,4 \text {, and 5) in } 3 \text { cases, } \\
\text { and probable (scores } 7 \text { and } 6 \text { ) in } 2 \text { cases }\end{array}$ \\
\hline
\end{tabular}

EMA, European Medicines Agency; HILI, herb-induced liver injury; RUCAM, Roussel Uclaf Causality Assessment Method.

HILI cases. These include prospective study design, adherence to LT thresholds, laboratorybased case classification as hepatocellular injury or cholestatic injury, and application of the criteria for assessing cases with an unintentional reexposure. For case presentation, HILI cohorts must be separated from DILI cohorts, the use of the updated RUCAM should be mentioned. Combined application of RUCAM with other CAMs is discouraged. RUCAM based causality gradings must be attributed to each HILI case, and for final evaluation characterization and decision only cases with a probable or highly probable causality gradings should be taken into consideration.

(II) Regulatory causality assessments are problematic in most HILI cases due to lacking use of a robust CAM such as RUCAM. Manufacturers and physicians that intend submitting spontaneous reports of assumed HILI to regulatory agencies are well advised to attach a RUCAM sheet with all relevant case data, scores of each key data element, and the final score with a causality grading. This allows regulatory reassessments and fair discussions with the stakeholders, preventing premature regulatory decision going public, potential loss of regulatory reputation, fruitless discussions in scientific journals, and court hearings.

(III) The HILI community will lose information on HILI characteristics, if HILI case evaluations do not include the use of a robust CAM such as RUCAM. These HILI cases are without scientific value and a waste of time and energy of the authors, aside from financial aspects if studies were supported by governmental funds gathered from taxpayers.

(IV) The recommendations listed above should be 


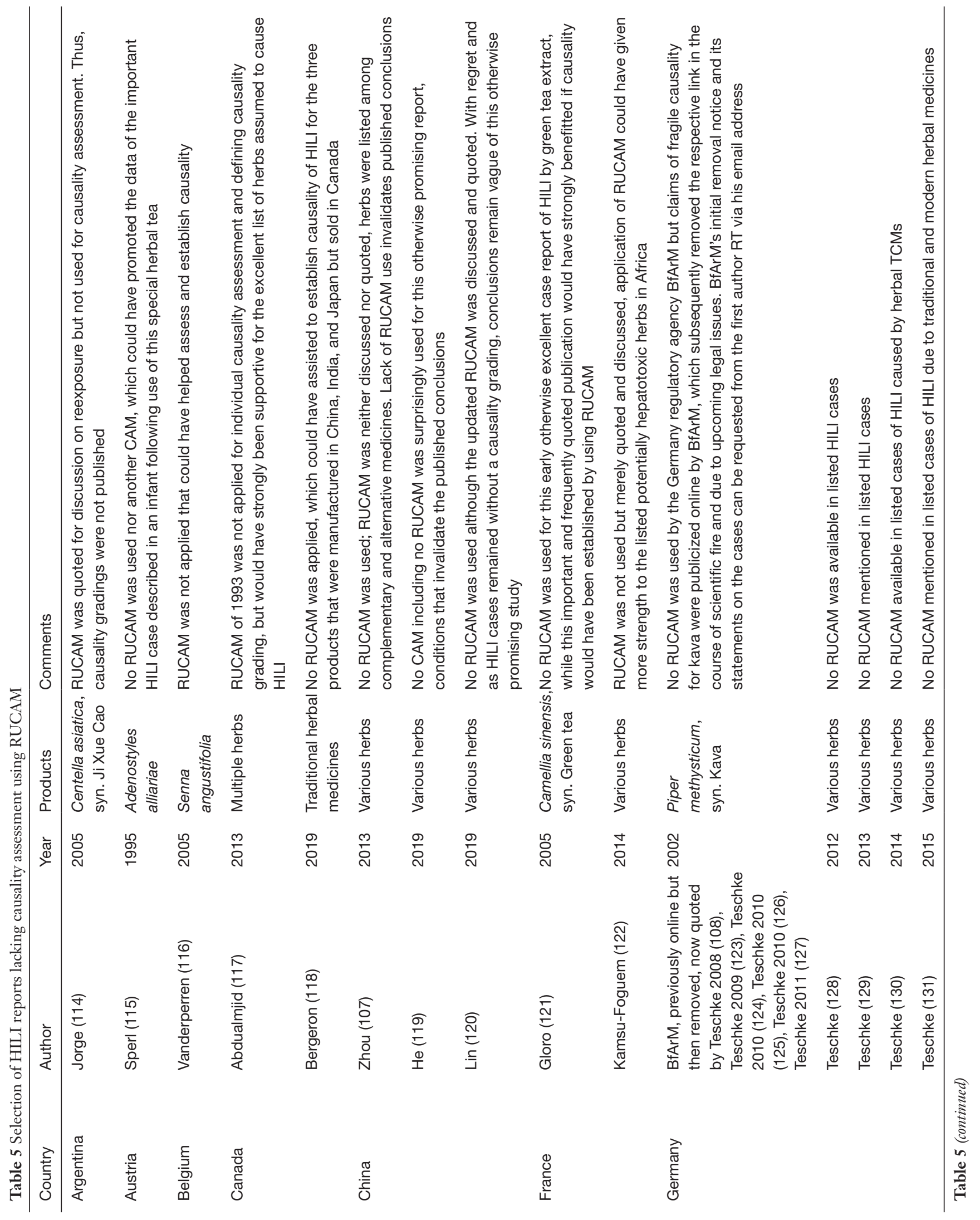




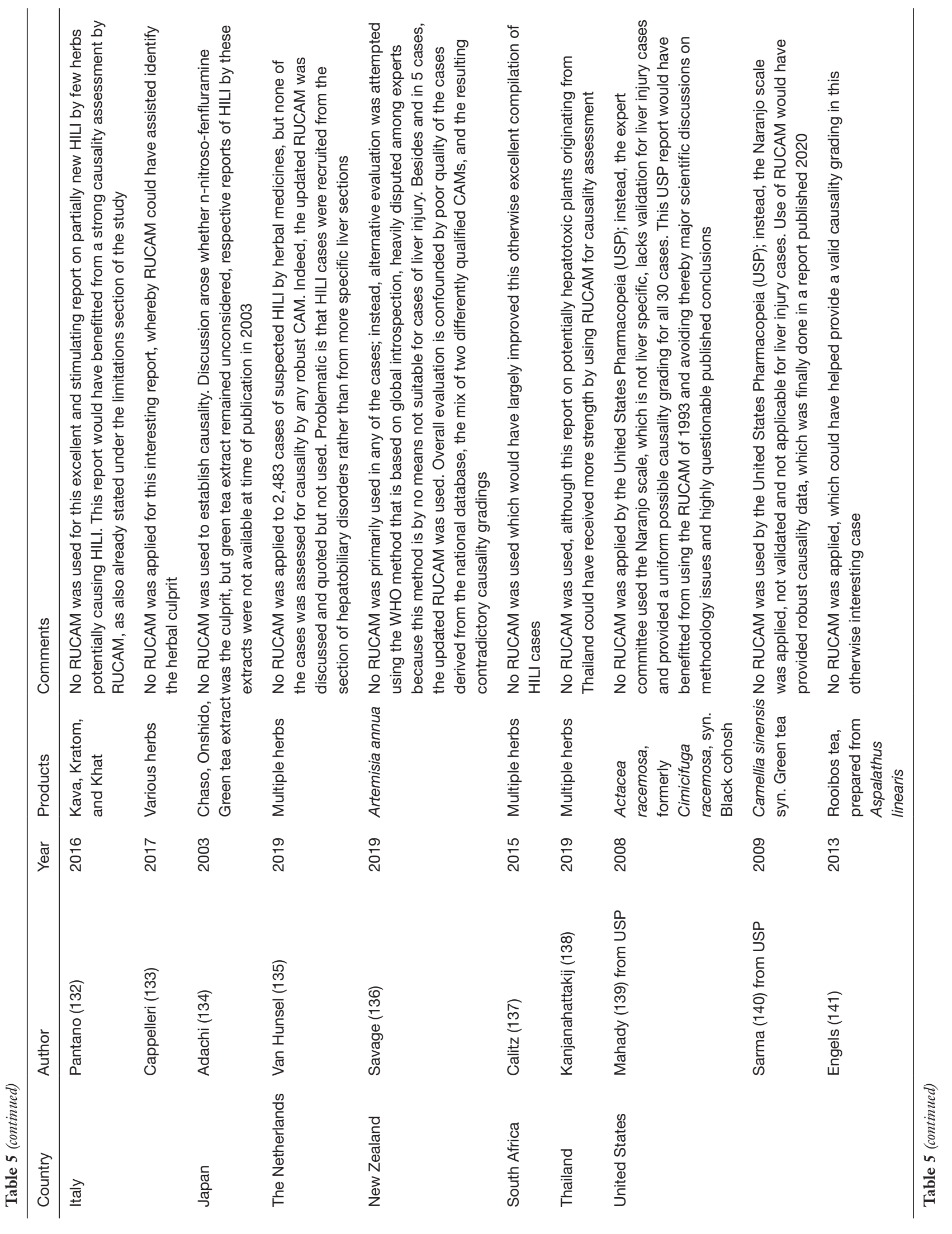




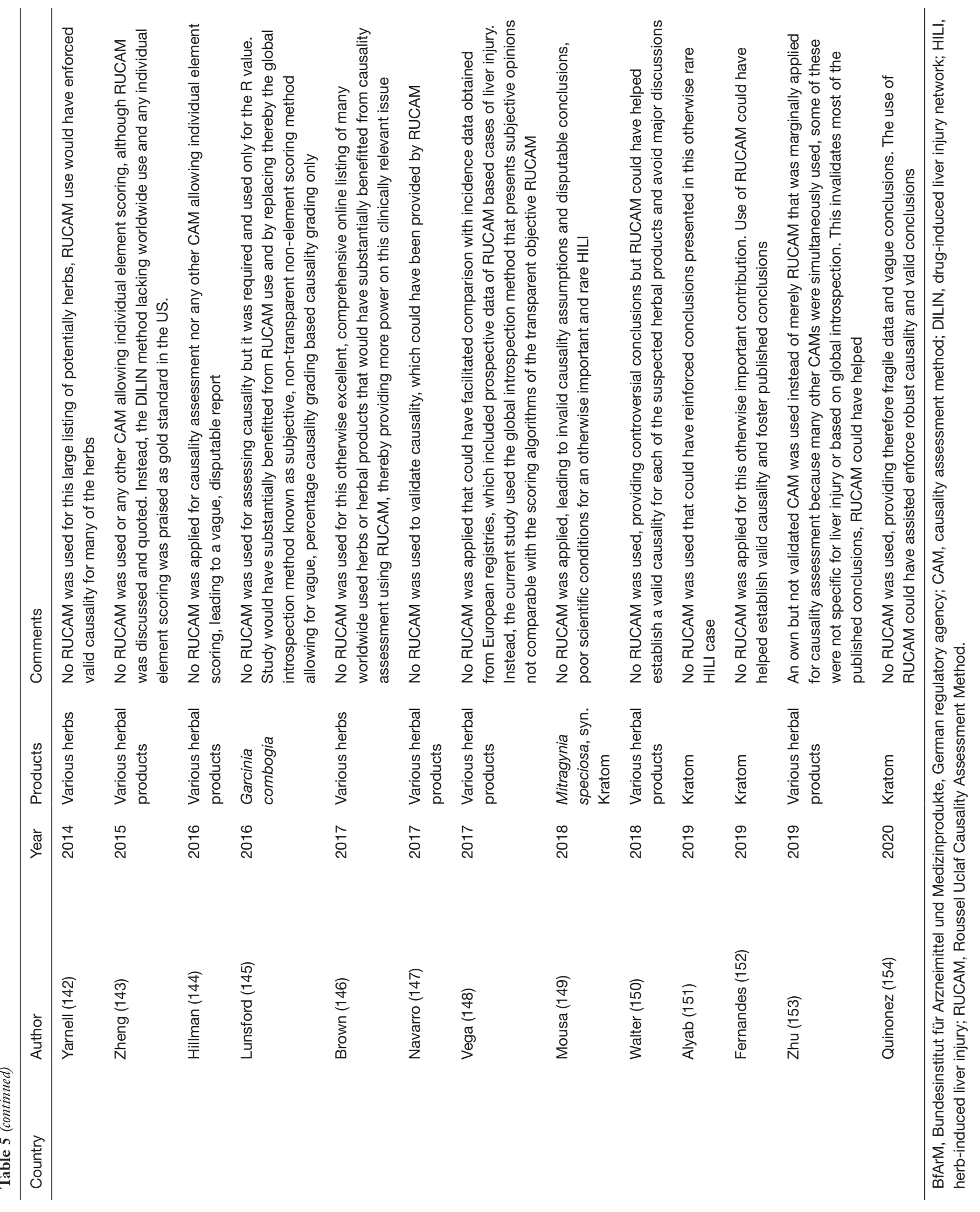


included in national guidelines on diagnosis of HILI. This will ensure comparability of HILI case features among various countries in West and East.

\section{Conclusions}

The current analysis presents details of 80 publications on a total number of 12,068 RUCAM based HILI cases from various countries around the world, in line with the userfriendly application of RUCAM smoothly used by reporting physicians and scientists. Among the assessable 11,404/12,068 HILI cases available for further evaluation, causality gradings were highly probable in $4.2 \%$ of the cases, probable in $15.5 \%$, possible in $70.3 \%$, and lower graded in $10.0 \%$. To improve the reporting of RUCAM based HILI cases in the future, recommendations include the strict adherence to the instructions outlined in the updated RUCAM and, in particular, to follow a prospective study design to ensure completeness of case data commonly allowing for high causality gradings. In an additional HILI group published in 4 reports, regulatory causality assessments were evidently problematic in virtually all HILI cases due to lacking use of a robust CAM such as RUCAM, but this primarily seems a specific problem of the German regulatory agency, not so of EMA that perfectly evaluated HILI cases using RUCAM. Apart from the 80 reports dealing with RUCAM based HILI cases, there were also 39 publications of HILI cases that did not benefit from causality assessments by a robust CAM like RUCAM. Conclusions derived from these reports have to be used with caution and are not helpful for the HILI community. In conclusion, RUCAM is well accepted in the world to assess causality in suspected HILI cases but additional efforts are now required to increase the quality of the reporting system.

\section{Acknowledgments}

Funding: None.

\section{Footnote}

Provenance and Peer Review: This article was commissioned by the editorial office, Translational Gastroenterology and Hepatology for the series "Liver Injury by Herbal Products". The article has undergone external peer review.

Conflicts of Interest: All authors have completed the ICMJE uniform disclosure form (available at http://dx.doi. org/10.21037/tgh-20-149). The series "Liver Injury by Herbal Products" was commissioned by the editorial office without any funding or sponsorship. RT served as the unpaid Guest Editor of the series and serves as an unpaid editorial board member of Translational Gastroenterology and Hepatology from Aug 2019 to Jul 2021. The authors have no other conflicts of interest to declare.

Ethical Statement: The authors are accountable for all aspects of the work in ensuring that questions related to the accuracy or integrity of any part of the work are appropriately investigated and solved.

Open Access Statement: This is an Open Access article distributed in accordance with the Creative Commons Attribution-NonCommercial-NoDerivs 4.0 International License (CC BY-NC-ND 4.0), which permits the noncommercial replication and distribution of the article with the strict proviso that no changes or edits are made and the original work is properly cited (including links to both the formal publication through the relevant DOI and the license). See: https://creativecommons.org/licenses/by-nc-nd/4.0/.

\section{References}

1. Sarges P, Steinberg JM, Lewis JH. Drug-induced liver injury: Highlights from a review of the 2015 literature. Drug Saf 2016;39:801-21.

2. Shahbaz O, Mahajan S, Lewis JH. Highlights of drug- and herb-induced liver injury in the literature from 2016: How best to translate new information into clinical practice? Expert Opin Drug Metab Toxicol 2017;13:935-51.

3. Real M, Barnhill MS, Higley C, et al. Drug-induced liver injury: highlights of the recent literature. Drug Saf 2019;42:365-87.

4. Teschke R, Larrey D, Melchart D, et al. Traditional Chinese Medicine (TCM) and Herbal Hepatotoxicity: RUCAM and the Role of Novel Diagnostic Biomarkers Such as MicroRNAs. Medicines (Basel) 2016;3:18.

5. Teschke R, Eickhoff A, Brown AC, et al. Diagnostic biomarkers in liver injury by drugs, herbs, and alcohol: Tricky dilemma after EMA correctly and officially retracted Letter of Support. Int J Mol Sci 2019;21:212.

6. Teschke R. Idiosyncratic DILI: Analysis of 46,266 Cases Assessed for Causality by RUCAM and Published From 2014 to Early 2019. Front Pharmacol 2019;10:730.

7. Danan G, Bénichou C. Causality assessment of adverse reactions to drugs - I. A novel method based on the 
conclusions of international consensus meetings: application to drug-induced liver injuries. J Clin Epidemiol 1993;46:1323-30.

8. Bénichou C, Danan G, Flahault A. Causality assessment of adverse reactions of drugs - II. An original model for validation of drug causality assessment methods: case reports with positive rechallenge. J Clin Epidemiol 1993;46:1331-6.

9. Danan G, Teschke R. RUCAM in drug and herb induced liver injury: The update. Int J Mol Sci 2015;17:14.

10. Teschke R, Zhu Y, Jing J. Herb induced liver injury (HILI) in the Asian region and current role of RUCAM for causality assessment in 11,160 published cases: Analysis and outlook. J Clin Transl Hepatol 2020. doi: 10.14218/ JCTH.220.00009. [In press].

11. Smith RJ, Bertilone C, Robertson AG. Fulminant liver failure and transplantation after use of dietary supplements. Med J Aust 2016;204:30-2.

12. Laube R, Liu K. An unwanted complement: Rare case of potential liver injury induced by an interaction between ginseng and atorvastatin. Br J Clin Pharmacol 2019;85:1612-3.

13. Stadlbauer V, Fickert P, Lackner C, et al. Hepatotoxicity of NONI juice: Report of two cases. World J Gastroenterol 2005;11:4758-60.

14. Barcelos STA, Dall'Oglio VM, de Araújo A, Cerski CTS, Álvares-da-Silva MR. Sinusoidal obstruction syndrome secondary the intake of Senecio brasiliensis: A case report. Ann Hepatol 2021;20:100138.

15. Yuen MF, Tam S, Fung J, et al. Traditional Chinese Medicine causing hepatotoxicity in patients with chronic hepatitis B infection: a 1-year prospective study. Aliment Pharmacol Ther 2006;24:1179-86.

16. Cheung WI, Tse ML, Ngan T, et al. Liver injury associated with the use of Fructus Psoraleae (Bol-gol-zhee or Bu-gu-zhi) and its related proprietary medicine. Clin Toxicol (Phila) 2009;47:683-5.

17. Chau TN, Cheung WI, Ngan T, et al. The Hong Kong Herb-Induced Liver Injury Network (HK-HILIN). Causality assessment of herb-induced liver injury using multidisciplinary approach and the Roussel Uclaf Causality Assessment Method (RUCAM). Clin Toxicol 2011;49:34-9.

18. Lin, G, Wang JY, Li N, et al. Hepatic sinusoidal obstruction syndrome associated with consumption of Gynura segetum. J Hepatol 2011;54:666-73.

19. Gao H, Li N, Wang JY, et al. Definitive diagnosis of hepatic sinusoidal obstruction syndrome induced by pyrrolizidine alkaloids. J Dig Dis 2012;13:33-9.

20. Lai RT, Wang H, Gui HL, et al. Clinical and Pathological Features in 138 Cases of Drug-Induced Liver Injury. Zhonghua Gan Zang Bing Za Zhi 2012;20:185-9.

21. Dong H, Slain D, Cheng J, et al. Eighteen cases of liver injury following ingestion of Polygonum multiflorum. Complement Ther Med 2014;22:70-4.

22. Hao K, Yu Y, He C, et al. RUCAM Scale-Based Diagnosis, Clinical Features and Prognosis of 140 Cases of DrugInduced Liver Injury. Zhonghua Gan Zang Bing Za Zhi 2014;22:938-41.

23. Gao H, Ruan JQ, Chen J, et al. Blood pyrrole-protein adducts as diagnostic and prognostic index in pyrrolizidine alkaloid-hepatic sinusoidal obstruction syndrome. Drug Des Devel Ther 2015;9:4861-8.

24. Ou P, Chen Y, Li B, et al. Causes, clinical features and outcomes of drug-induced liver injury in hospitalized patients in a Chinese tertiary care hospital. SpringerPlus 2015;4:802.

25. Wang J, Ma Z, Niu M, et al. Evidence chain-based causality identification in herb-induced liver injury: Exemplification of a well-known liver-restorative herb Polygonum multiflorum. Front Med 2015;9:457-67.

26. Zhu Y, Liu SH, Wang JB, et al. Clinical Analysis of Druginduced Liver Injury Caused by Polygonum multiflorum and its Preparations. Zhongguo Zhong Xi Yi Jie He Za Zhi 2015;35:1442-7.

27. Zhang P, Ye Y, Yang X, et al. Systematic review on Chinese herbal medicine induced liver injury. Evid Based Complement Alternat Med 2016;2016:3560812.

28. Zhu Y, Niu M, Chen J, et al. Comparison between Chinese herbal medicine and Western medicine-induced liver injury of 1985 patients. J Gastroenterol Hepatol 2016;31:1476-82.

29. Li CY, He Q, Gao D, et al. Idiosyncratic drug-induced liver injury linked to Polygonum multiflorum: A case study by pharmacognosy. Chin J Integr Med 2017;23:625-30.

30. Chow HC, So TH, Choi HCW, et al. Medicine herbsinduced liver injury from an oncological perspective with RUCAM. Integr Cancer Ther 2019;18:10.1177/15347354 19869479.

31. Jing J, Wang RL, Zhao XY, et al. Association between the concurrence of pre-existing chronic liver disease and worse prognosis in patients with an herb - Polygonum multiflorum thunb. induced liver injury: a case-control study from a specialised liver disease center in China. BMJ Open 2019;9:e023567.

32. Li A, Gao M, Zhao N, et al. Acute liver failure associated 
with Fructus Psoraleae: a case report and literature review. BMC Complement Altern Med 2019;19:84.

33. Liu Y, Wang W, Sun M, et al. Polygonum multifloruminduced liver injury: clinical characteristics, risk factors, material basis, action mechanism and current challenges. Front Pharmacol 2019;10:1467.

34. Shen T, Liu Y, Shang J, et al. Incidence and etiology of drug-induced liver injury in Mainland China. Gastroenterology 2019;156:2230-2241.e11..

35. Tan Y, Chen H, Zhou X, et al. RUCAM-based assessment of liver injury by xian-tian-guo (Swietenia macrophylla) seeds, a plant used for treatment of hypertension and diabetes. Ann Hepatol 2019;18:406-7.

36. Zhu Y, Niu M, Wang JB, et al. Predictors of poor outcomes in 488 patients with herb-induced liver injury. Turk J Gastroenterol 2019;30:47-58.

37. Gao Y, Wang Z, Tang J, et al. New incompatible pair of TCM: Epimedii Folium combined with Psoraleae Fructus induces idiosyncratic hepatotoxicity under immunological stress conditions. Front Med 2020;14:68-80.

38. Xia C, Liu Y, Yao H, et al. Causality assessment of skyfruit-induced liver injury using the updated RUCAM: a case report and review of the literature. J Int Med Res 2020;48:300060520917569.

39. Cárdenas A, Restrepo JC, Sierra F, et al. Acute hepatitis due to shen-min: a herbal product derived from Polygonum multiflorum. J Clin Gastroent 2006;40:629-32.

40. Parlati L, Voican CS, Perlemuter K, et al. Aloe verainduced acute liver injury: A case report and literature review. Clin Res Hepatol Gastroenterol 2017;41:e39-42.

41. Teschke R, Bahre R. Severe hepatotoxicity by Indian Ayurvedic herbal products: A structured causality assessment. Ann Hepatol 2009;8:258-66.

42. Teschke R, Glass X, Schulze J. Herbal hepatotoxicity by Greater Celandine (Chelidonium majus): Causality assessment of 22 spontaneous reports. Regul Toxicol Pharmacol 2011;61:282-91.

43. Teschke R, Glass X, Schulze J, et al. Suspected Greater Celandine hepatotoxicity: Liver specific causality evaluation of published case reports from Europe. Eur J Gastroenterol Hepatol 2012;24:270-80.

44. Douros A, Bronder E, Andersohn F, et al. Herb-induced liver injury in the Berlin Case-Control Surveillance Study. Int J Mol Sci 2016;17:114.

45. Teschke R, Zhang L, Long H, et al. Traditional Chinese Medicine and herbal hepatotoxicity: A tabular compilation of reported cases. Ann Hepatol 2015;14:7-19.

46. Melchart D, Hager S, Albrecht S, et al. Herbal Traditional
Chinese Medicine and suspected liver injury: A prospective study. World J Hepatol 2017;9:1141-57.

47. Anderson N, Borlak J. Hepatobiliary Events in Migraine Therapy With Herbs-The Case of Petadolex, A Petasites Hybridus Extract. J Clin Med 2019;8:652.

48. Gerhardt F, Benesic A, Tillmann HL, et al. Iberogastinduced acute liver failure-reexposure and in vitro assay support causality. Am J Gastroenterol 2019;114:1358-9.

49. Teschke R, Xuan TD. Suspected herb induced liver injury by green tea extracts: Critical review and case analysis applying RUCAM for causality assessment. Japanese Journal of Gastroenterology and Hepatology 2019;1:1-16.

50. Philips CA, Paramaguru R, Joy AK, et al. Clinical outcomes, histopathological patterns, and chemical analysis of Ayurveda and herbal medicine associated with severe liver injury-A single-center experience from southern India. Indian J Gastroenterol 2018;37:9-17.

51. Philips CA, Augustine P, Rajesh S, et al. Complementary and alternative medicine-related drug-induced liver injury in Asia. J Clin Transl Hepatol 2019;7:263.

52. Lapi F, Gallo E, Giocaliere E, et al. Acute liver damage due to Serenoa repens: a case report. Br J Clin Pharmacol 2010;69:558-60.

53. Mazzanti G, Di Sotto A, Vitalone A. Hepatotoxicity of green tea: an update. Arch Toxicol 2015;89:1175-91.

54. Mazzanti G, Moro P, Raschi E, et al. Adverse reactions to dietary supplements containing red yeast rice: assessment of cases from the Italian surveillance system: safety of red yeast rice dietary supplements. Br J Clin Pharmacol 2017;83:894-908.

55. Tsuda T, Yashiro S, Gamo Y, et al. Discrepancy between clinical course and drug-induced lymphocyte stimulation tests in a case of saireito-induced liver injury accompanied by Sjögren syndrome. J Altern Complement Med 2010;16:501-5.

56. Hisamochi A, Kage M, Arinaga T, et al. Drug-induced liver injury associated with Agaricus blazei Murill which is very similar to autoimmune hepatitis. Clin J Gastroenterol 2013;6:139-44.

57. Ahn BM. Herbal Preparation-Induced Liver Injury. Korean J Gastroenterol 2004;44:113-25.

58. Seo JC, Jeon WJ, Park SS, et al. Korean J Hepatol 2006;12:74-81.

59. Kang SH, Kim JI, Jeong KH, et al. Clinical characteristics of 159 cases of acute toxic hepatitis. Korean J Hepatol 2008;14:483-92.

60. Sohn CH, Cha MI, Oh BJ, et al. Liver transplantation for acute toxic hepatitis due to herbal medicines and 
preparations. J Korean Soc Clin Toxicol 2008;6:110-6

61. Kang HS, Choi HS, Yun TJ, et al. A case of acute cholestatic hepatitis induced by Corydalis speciosa Max. Korean J Hepatol 2009;15: 517-23.

62. Kim SY, Yim HJ, Ahn JH, et al. Two cases of toxic hepatitis caused by arrowroot juice. Korean J Hepatol 2009;15:504-9.

63. Bae SH, Kim DH, Bae YS, et al. Toxic hepatitis associated with Polygoni multiflori. Korean J Hepatol 2010;16:182-6.

64. Yang HN, Kim DJ, Kim YM, et al. Aloe-induced toxic hepatitis. J Korean Med Sci 2010;25:492-5.

65. Jung KA, Min HJ, Yoo SS, et al. Drug-induced liver injury: Twenty five cases of acute hepatitis following ingestion of Polygonum multiflorum Thun. Gut Liver 2011;5:493-9.

66. Kim YJ, Ryu SL, Shim JW, et al. A pediatric case of toxic hepatitis induced by Hovenia dulcis. Pediatr Gastroenterol Hepatol Nutr 2012;15:111-6.

67. Suk KT, Kim DJ, Kim CH, et al. A prospective nationwide study of drug-induced liver injury in Korea. Am J Gastroenterol 2012;107:1380-7.

68. Lee J, Shin JS, Kim MR, et al. Liver enzyme abnormalities in taking traditional herbal medicine in Korea: A retrospective large sample cohort study of musculoskeletal disorder patients. J Ethnopharmacol 2015;169:407-12.

69. Lee WJ, Kim HW, Lee HY, et al. Systematic review on herb-induced liver injury in Korea. Food Chem Toxicol 2015;84:47-54.

70. Woo HJ, Kim HY, Choi ES, et al. Drug-induced liver injury: A 2-year retrospective study of 1169 hospitalized patients in a single medical center. Phytomedicine 2015;22:1201-5.

71. Cho JH, Oh DS, Hong SH, et al. A nationwide study of the incidence rate of herb-induced liver injury in Korea. Arch Toxicol 2017;91:4009-15.

72. Wai CT. Presentation of drug-induced liver injury in Singapore. Singapore Med J 2006;47:116-20.

73. Teo DCH, Ng PSL, Tan SH, et al. Drug-induced liver injury associated with Complementary and Alternative Medicine: a review of adverse event reports in an Asian community from 2009 to 2014. BMC Complement Altern Med 2016;16:192.

74. Awortwe C, Makiwane M, Reuter H, et al. Critical evaluation of causality assessment of herb-drug interactions in patients. Br J Clin Pharmacol 2018;84:679-93.

75. Andrade RJ, Lucena MI, Fernández MC, et al. Spanish Group for the Study of Drug-induced Liver Disease. Drug-induced liver injury: an analysis of 461 incidences submitted to the Spanish registry over a 10 -year period.
Gastroenterology 2005;129:512-21.

76. Jimenez-Saenz M, Martinez-Sanchez M del C. Acute hepatitis associated with the use of green tea infusions. J Hepatol 2006;44:616-7.

77. García-Cortés M, Borraz Y, Lucena MI, et al. Liver injury induced by "natural remedies": an analysis of cases submitted to the Spanish Liver Toxicity Registry. Rev Esp Enferm Dig 2008;100:688-95.

78. García-Cortés M, Lucena MI, Pachkoria K, et al. Evaluation of Naranjo Adverse Drug Reactions Probability Scale in causality assessment of drug-induced liver injury. Aliment Pharmacol Ther 2008;27:780-9.

79. Sáez-González E, Conde I, Díaz-Jaime FC, et al. Iberogast-induced severe hepatotoxicity leading to liver transplantation. Am J Gastroenterol 2016;111:1364-5.

80. Medina-Caliz I, Garcia-Cortes M, Gonzalez-Jimenez A, et al. Herbal and dietary supplement-induced liver injuries in the Spanish DILI Registry. Clin Gastroenterol Hepatol 2018;16:1495-502.

81. Björnsson E, Olsen R. Serious adverse liver reactions associated with herbal weight-loss supplements. J Hepatol 2007;47:295-7; author reply 297-8.

82. Ruperti-Repilado FJ, Haefliger S, Rehm S, et al. Danger of herbal tea: a case of acute cholestatic hepatitis due to Artemisia annua tea. Front Med (Lausanne) 2019;6:221.

83. Yilmaz B, Yilmaz B, Akta B, et al. Lesser celandine (pilewort) induced acute toxic liver injury: The first case report worldwide. World J Hepatol 2015;7:285-8.

84. Papafragkakis C, Ona MA, Reddy M, et al. Acute Hepatitis after Ingestion of a Preparation of Chinese Skullcap and Black Catechu for Joint Pain. Case Reports Hepatol 2016;2016:4356749.

85. Kesavarapu K, Kang M, Shin JJ, et al. Yogi Detox Tea: A Potential Cause of Acute Liver Failure. Case Rep Gastrointest Med 2017;2017:3540756.

86. Kothadia JP, Kaminski M, Samant H, et al. Hepatotoxicity Associated with Use of the Weight Loss Supplement Garcinia cambogia: A Case Report and Review of the Literature. Case Reports Hepatol 2018;2018:6483605.

87. Surapaneni BK, Le M, Jakobovits J, Vinayek R, et al. A Case of Acute Severe Hepatotoxicity and Mild Constriction of Common Bile Duct Associated With Ingestion of Green Tea Extract: A Clinical Challenge. Clin Med Insights Gastroenterol 2018;11:1179552218779970.

88. Imam Z, Khasawneh M, Jomaa D, et al. Drug Induced Liver Injury Attributed to a Curcumin Supplement. Case Rep Gastrointest Med 2019;2019:6029403.

89. Osborne CS, Overstreet AN, Rockey DC, et al. Drug- 
Induced Liver Injury Caused by Kratom Use as an Alternative Pain Treatment Amid an Ongoing Opioid Epidemic. J Investig Med High Impact Case Rep 2019;7:2324709619826167.

90. Oketch-Rabah HA, Roe AL, Rider CV, et al. United States Pharmacopeia (USP) comprehensive review of the hepatotoxicity of green tea extracts. Toxicol Rep 2020;7:386-402.

91. Schimmel J, Dart RC. Kratom (Mitragyna Speciosa) Liver Injury: A Comprehensive Review. Drugs 2020;80:263-83.

92. Danan G, Teschke R. Drug-induced liver injury: Why is the Roussel Uclaf Causality Assessment Method (RUCAM) still used 25 years after its launch? Drug Saf 2018;41:735-43.

93. Danan G, Teschke R. Roussel Uclaf Causality Assessment Method for Drug-Induced Liver Injury: Present and Future. Front Pharmacol 2019;10:853.

94. Teschke R, Danan G. Causality Assessment Methods in Drug-Induced Liver Injury. In: Chen M, Will Y. editors. Drug-Induced Liver Toxicity. Methods in Pharmacology and Toxicology. 1st edition. New York, NY: Humana, 2018:555-94.

95. Teschke R, Danan G. Drug induced liver injury: Mechanisms, diagnosis, and clinical management. In: Radu-Ionita F, Pyrsopoulos NT, Jinga M, et al. editors. Liver Diseases: A Multidisciplinary Textbook. Springer London Ltd., 2020:95-105.

96. Teschke R, Schwarzenboeck A, Frenzel C, et al. The mystery of the Hawaii liver disease cluster in summer 2013: A pragmatic and clinical approach to solve the problem. Ann Hepatol 2016;15:91-109.

97. Teschke R, Eickhoff A. The Honolulu liver disease cluster at the Medical Center: Its mysteries and challenges. Int J Mol Sci 2016;17:476.

98. Yang H, Guo D, Xu Y, et al. Comparison of different liver test thresholds for drug-induced liver injury: Updated RUCAM versus other methods. Front Pharmacol 2019;10:816.

99. Teschke R, Frenzel C, Schulze J, et al. Herbalife hepatotoxicity: Evaluation of cases with positive reexposure tests. World J Hepatol 2013;5:353-63.

100. Teschke R, Genthner A, Wolff A, et al. Herbal hepatotoxicity: Analysis of cases with initially reported positive re-exposure tests. Dig Liver Dis 2014;46:264-9.

101. Teschke R, Schulze J, Schwarzenboeck A, et al. Herbal hepatotoxicity: suspected cases assessed for alternative causes. Eur J Gastroenterol Hepatol 2013;25:1093-8. 102. Teschke R, Frenzel C, Wolff A, et al. Drug induced liver injury: accuracy of diagnosis in published reports. Ann Hepatol 2014;13:248-55.

103. Teschke R. Review. Top-ranking drugs out of 3312 druginduced liver injury cases evaluated by the Roussel Uclaf Causality Assessment Method. Expert Opin Drug Metab Toxicol 2018;14:1169-87.

104. Teschke R, Eickhoff A, Wolff A, et al. Liver injury from herbs and "dietary supplements": Highlights of a literature review from 2015 to 2017. Curr Pharmacol Rep 2018;4:120-31.

105.Jing J, Teschke R. Traditional Chinese medicine (TCM) and herb induced liver injury: comparison with drug induced liver injury. J Clin Transl Hepatol 2018;6:57-68.

106.Lee J, Shin J, Lee YJ, et al. Battle over herb-induced liver injury: Low prevalence confirmed through secondary evaluation and research team's clarifying rebuttal to unwarranted public claims. J Altern Complement Med 2019;25:260-4.

107.Zhou Y, Yang L, Liao Z, et al. Epidemiology of druginduced liver injury in China: a systematic analysis of the Chinese literature including 21,789 patients. Eur J Gastroenterol Hepatol 2013;25:825-9.

108. Teschke R, Schwarzenboeck A, Hennermann KH. Kava hepatotoxicity: a clinical survey and critical analysis of 26 suspected cases. Eur J Gastroenterol Hepatol 2008;20:1182-93.

109. Teschke R. Black cohosh and suspected hepatotoxicity inconsistencies, confounding variables, and prospective use of a diagnostic causality algorithm: A critical review. Menopause 2010;17:426-40.

110. Teschke R, Frenzel C, Schulze J, et al. Spontaneous reports of primarily suspected herbal hepatotoxicity by Pelargonium sidoides: was causality adequately ascertained? Regul Toxicol Pharmacol 2012;63:1-9.

111. Teschke R, Eickhoff A, Schulze J, et al. Petadolex®, a herbal extract for migraine prophylaxis with spontaneous case reports of disputed liver injury: Robust causality evaluation by RUCAM, the Roussel Uclaf Causality Assessment Method. Eur J Pharmaceut Med Res 2016;3:154-77.

112.EMA. Assessment of case reports connected to herbal medicinal products containing cimicifugae racemosae rhizoma (black cohosh, root). Issued May 8, 2007. Accessed 14 March 2020. Available online: http://www. ema.europa.eu/docs/en_GB/document_library/Herbal_-HMPC_assessment_report/2010/02/WC500074167.pdf

113.Kuchta K, Schmidt M, Nahrstedt A. Perspectives. German Kava ban lifted by court: The alleged hepatotoxicity of Kava (Piper methysticum) as a case of ill-defined herbal 
drug identity, lacking quality control, and misguided regulatory politics. Planta Medica 2015;81:1647-53.

114.Jorge OA, Jorge AD. Hepatotoxicity associated with the ingestion of Centella asiatica. Rev Esp Enferm Dig 2005;97:115-24.

115. Sperl W, Stuppner H, Gassner I, et al. Reversible hepatic veno-occlusive disease in an infant after consumption of pyrrolizidine-containing herbal tea. Eur J Pediatr 1995;154:112-6.

116. Vanderperren B, Rizzo M, Angenot L, et al. Acute liver failure with renal impairment related to the abuse of senna anthroquinone glycosides. Ann Pharmacother 2005;39:1353-7.

117.Abdualmjid RJ, Sergi C. Hepatotoxic botanicals - an evidence-based systematic review. J Pharm Pharm Sci 2013;16:376-404.

118. Bergeron F, Hussaini T, Yoshida E. Alternative medicine products causing acute liver injury: Pandora's box open. Can Liver J 2019;2:1-3.

119.He S, Zhang C, Zhou P, et al. Herb-induced liver injury: phylogenetic relationship, structure-toxicity relationship, and herb-ingredient network analysis. Int J Mol Sci 2019;20:3633.

120. Lin NH, Yang HW, Su YJ, et al. Herb induced liver injury after using herbal medicine: A systemic review and casecontrol study. Medicine 2019;98:e14992.

121. Gloro R, Hourmand-Ollivier I, Mosquet B, et al. Fulminant hepatitis during self-medication with hydroalcoholic extract of green tea. Eur J Gastroenterol Hepatol 2005;17:1135-7.

122.Kamsu-Foguem B, Foguem C. Adverse drug reactions in some African herbal medicine: literature review and stakeholders' interview. Integr Med Res 2014;3:126-32.

123. Teschke R, Wolff A. Kava hepatotoxicity: Regulatory data selection and causality assessment. Dig Liver Dis 2009;41:891-901.

124. Teschke R. Kava hepatotoxicity - a clinical review. Ann Hepatol 2010;9:251-65.

125. Teschke R. Kava hepatotoxicity: pathogenetic aspects and prospective considerations. Liver Int 2010;30:1270-9.

126. Teschke R, Fuchs J, Bahre R, et al. Kava hepatotoxicity: comparative study of two structured quantitative methods for causality assessment. J Clin Pharm Ther 2010;35:545-63.

127. Teschke R, Wolff A. Regulatory causality evaluation methods applied in kava hepatotoxicity: Are they appropriate? Regul Toxicol Pharmacol 2011;59:1-7. 128. Teschke R, Wolff A, Frenzel C, et al. Herbal hepatotoxicity: A tabular compilation of reported cases. Liver Int 2012;32:1543-56.

129. Teschke R, Schwarzenboeck A, Eickhoff A, et al. Clinical and causality assessment in herbal hepatotoxicity. Expert Opin Drug Saf 2013;12:339-66.

130. Teschke R. Traditional Chinese Medicine induced liver injury. J Clin Transl Hepatol 2014;2:80-94.

131. Teschke R, Eickhoff A. Herbal hepatotoxicity in traditional and modern medicine: Actual key issues and new encouraging steps. Front Pharmacol 2015;6:72.

132.Pantano F, Tittarelli R, Mannocchi G, et al. Hepatotoxicity Induced by "the $3 \mathrm{Ks}$ ": Kava, Kratom and Khat. Int J Mol Sci 2016;17:580.

133. Cappelleri G, Sangiovanni E, Dell'Agli M. A case of serial liver injury induced by plant food supplements in a young healthy man. J Clin Gastroenterol Treat 2017;3:047.

134. Adachi M, Saito H, Kobayashi H, et al. Hepatic injury in 12 patients taking the herbal weight loss aids Chaso or Onshido. Ann Intern Med 2003;139:488-92.

135.van Hunsel F, van de Koppel S, Skalli S, et al. Analysis of hepatobiliary disorder reports associated with the use of herbal medicines in the global suspected ADR database Vigibase. Front Pharmacol 2019;10:1326.

136. Savage RL, Hill GR, Barnes J, et al. Suspected hepatotoxicity with a supercritical carbon dioxide extract of Artemisia annua in grapeseed oil used in New Zealand. Front Pharmacol 2019;10:1448.

137. Calitz C, du Plessis L, Gouws C, et al. Herbal hepatotoxicity: current status, examples, and challenges. Expert Opin Drug Metab Toxicol 2015;11:1551-65.

138. Kanjanahattakij N, Kwankhao P, Vathesatogkit, P, et al. Herbal or traditional medicine consumption in a Thai worker population: pattern of use and therapeutic control in chronic diseases. BMC Complement Altern Med 2019;19:258.

139. Mahady GB, Low Dog T, Barrett ML, et al. United States Pharmacopeia review of the black cohosh case reports of hepatotoxicity. Menopause 2008;15:628-38.

140. Sarma DN, Barrett ML, Chavez ML, et al. Safety of en tea extracts: a systematic review by the US Pharmacopeia. Drug Saf 2008;31:469-84.

141. Engels M, Wang C, Matoso A, et al. Tea not tincture: hepatotoxicity associated with Rooibos herbal tea. ACG Case Rep J 2013;1:58-60.

142. Yarnell E, Abascal K. Hepatotoxicity of botanicals. Alternat Complement Ther 2014;20:136-44.

143.Zheng EX, Navarro VJ. Liver injury from herbal, dietary and weight loss supplements: a review. J Clin Transl 
Hepatol 2015;3:93-8.

144.Hillman L, Gottfried M, Whitsett M, et al. Clinical features and outcomes of complementary and alternative medicine induced acute liver failure and injury. Am

J Gastroenterol 2016;111:958-65. Erratum in: Am J

Gastroenterol 2016;111:1504.

145.Lunsford KE, Bodzin AS, Reino DC, et al. Dangerous dietary supplements: Garcinia cambogia-associated hepatic failure requiring transplantation. World J Gastroenterol 2016;22:10071-6.

146. Brown AC. Liver toxicity related to herbs and dietary supplements: Online table of case reports. Part 2 of 5 series. Food Chem Toxicol 2017;107:472-501.

147.Navarro VJ, Khan I, Björnsson E, et al. Liver injury from herbal and dietary supplements. Hepatology 2017;65:363-73.

148. Vega M, Verma M, Beswick D, et al. The incidence of drug- and herbal and dietary supplement-induced liver injury: preliminary findings from gastroenterologist-based surveillance in the population of the State of Delaware. Drug Saf 2017;40:783-7.

doi: $10.21037 / \operatorname{tgh}-20-149$

Cite this article as: Teschke R, Eickhoff A, Schulze J, Danan G. Herb induced liver injury (HILI) with 12,068 worldwide cases published with causality assessments by Roussel Uclaf Causality Assessment Method (RUCAM): an overview. Transl Gastroenterol Hepatol 2021;6:51.
149. Mousa MS, Sephien A, Gutierrez J, et al. N-Acetylcysteine for acute hepatitis induced by Kratom herbal tea. Am J Ther 2018;25:e550-1.

150. Walter J, Navarro V, Rossi S, Drug-induced liver injury associated with weight loss supplements. Curr Hepatol Rep 2018;17:245-53.

151.Aldyab M, Ells PF, Bui R, et al. Kratom-induced cholestatic liver injury mimicking anti-mitochondrial antibody-negative primary biliary cholangitis: A case report and review of literature. Gastroenterology Res 2019;12:211-5.

152.Fernandes CT, Iqbal U, Tighe SP, et al. Kratominduced cholestatic liver injury and its conservative management. J Investig Med High Impact Case Rep 2019;7:2324709619836138.

153.Zhu J, Chen M, Borlak J, et al. The landscape of hepatobiliary adverse reactions across 53 herbal and dietary supplements reveals immune-mediated injury as a common cause of hepatitis. Arch Toxicol 2020;94:273-93. 154. Quinonez J, Atwal T. Kratom induced hepatotoxicity: A case report. Int J Hepatol Gastroenterol 2020;6:001-004. 